\title{
RISK FACTORS AND DIAGNOSIS OF INTESTINAL PARASITIC INFECTIONS IN IRRITABLE BOWEL SYNDROME PATIENTS

\author{
By
}

EMAN M. H. MÉABED ${ }^{1 *}$, WAFAA Y. ABDEL WAHED ${ }^{2}$, AHMED A. GOMAA ${ }^{3}$, and ESSAM A. HASSAN ${ }^{3}$

Departments of Parasitology ${ }^{1}$, Public Health and Community Medicine ${ }^{2}$, and

Tropical Medicine ${ }^{3}$, Faculty of Medicine, Fayoum University, Fayoum, Egypt

(*Correspondence: emeabed@gmail.com/emm02@fayoum.edu.eg; Mob: 00201008981791)

\begin{abstract}
Irritable bowel syndrome (IBS) is still an ambiguous disorder of the gastrointestinal function. Several theories have been postulated as regard its underlying patho-physiology. Infection with intestinal parasites has been evaluated as a possible etiology with contradictory results. This study compared IBS cases with normal population in Fayoum Governorate as regard infection with parasites, and to detect their possible associated risk factors. Stool samples were parasitologically examined by concentrated sedimentation, stained with Lugol's iodine, trichrome. The RIDA ${ }^{\circledR}$ QUICK Cryptosporidium/Giardia/Entamoeba Combi kits were applied. Stool samples were cultured on Jones and Loeffler's slope media for detection of Blastocystis spp. \& D. fragilis, respectively. Blastocystis spp., D. fragilis \& Cryptosporidium were the commonest parasites in the examined samples. Blastocystis spp. was the only parasite significantly associated with IBS. Contact with animals was a common risk factor for the three prevalent parasites. Low socioeconomic standard was a risk for Blastocystis \& Cryptosporidium infections as well as consumption of contaminated food and/or drink was associated with Blastocystis infection.
\end{abstract}

Keywords: Fayoum, Irritable bowel syndrome, Blastocystis spp., Cryptosporidium, D. fragilis.

\section{Introduction}

Irritable bowel syndrome (IBS) is an unexplained abnormality of the gastrointestinal tract function, affecting approximately $12 \%$ of persons globally (Morgan et al, 2012). Several factors may combine in IBS patients that account for clinical symptoms. These include altered gut reactivity in response to luminal or psychological stimuli and visceral or gut hypersensitivity, neurotransmitter imbalance, in addition to psychosocial factors (Jimenez-Gonzalez et al, 2012).

A subset of IBS was described in cases with a preceding infective gastroenteritis causing post infectious IBS (PI-IBS). Qualitative reviews reported PI-IBS prevalence rates from $4 \%$ to $31 \%$ ( $10 \%$ pooled incidence), and estimated relative risk ranging from 2.5 to 11.9 between infectious gastroenteritis and PI-IBS (Thabane et al, 2007). Many infectious agents were incriminated including parasitic infections. Parasitic gastroenteritis infected cases were at risk of developing IBS at a rate of $41.9 \%$, while bac- terial gastroenteritis infected cases had a rate of $13.8 \%$ (Klem et al, 2017).

Several parasites might be contributed factors to the development of IBS, including Entamoeba spp., Giardia spp., Blastocystis spp., Dientamoeba fragilis, Trichinella spp. Cystoisospora belli, Cryptosporidium spp., and Cyclospora cayetanensis, (Stark et al, 2007; Morgan et al, 2012; El-Badry et al, 2018). The infections with these parasites can be asymptomatic, or linked to various nonspecific gastrointestinal symptoms including diarrhea, abdominal pain, fatigue, vomiting, constipation, anorexia, and flatulence which simulates the symptoms of IBS (Wawrzyniak et al, 2013). Several studies supported a positive role for these parasites in IBS (Cekin et al, 2012; Yakoob et al, 2010a, b), while others didn't (Stark et al, 2007; Morgan et al, 2012). The results were controversial between developed and developing countries and influenced by the sensitivity of detection methods (Krogsgaard $e t$ $a l$, 2015). In addition, the IBS diagnosis classically depended on clinical evaluation 
of cases according to Rome III criteria without commitment to stool examination to diagnose parasitic gastroenteritis (Yakoob et $a l, 2010 \mathrm{~b})$. Specific stool examination for detection of intestinal parasites is generally performed when diarrhea is the major manifestation of IBS (Ramirez-Miranda et al, 2010).

The study aimed to detect the intestinal parasitic infections and their contributing risk factors in cases presenting with IBS symptoms, in comparison with normal volunteers in Fayoum Governorate, Egypt.

\section{Material and methods}

This is a case-control study. The sample size was calculated using OpenEpi to be 85 per group based on a previouse study (Jimenez-Gonzalez et al, 2012). The hypothetical power of the study was $80 \%$, the ratio of cases to control was $1: 1$, the proportion of the parasitic infections in cases and control groups was designed to be $31.3 \%$ \& $13 \%$, respectively. Out of 2000 patients who visited the Tropical Medicine and Gastroenterology outpatient clinic at Fayoum University Hospital from January to May 2016, about 208 cases proved to be IBS, of them 90 cases gave consent to share in the study and met the inclusion criteria. The control group was selected from attendees of the Ophthalmology clinic (coming for assessment of visual acuity) of matched age, sex, SES as cases, without any GIT complains.

The study was approved by the Ethics Committee, Faculty of Medicine, Fayoum University, and informed consents were obtained the participants. To be included in the study, IBS cases should have normal colonoscopy, diagnosed and classified as IBS according to the Rome III criteria (Longstreth et al, 2006). Participants should confirm non-use of antibiotics or anti-protozoal agents in the preceding month, and stool samples should be negative for the tested pathogenic bacterial infections.

Questionnaire interview: This included questions about personal, demographic, clinic- cal data suggestive of IBS according to the Rome III criteria. Socioeconomic standard (SES) was graded according to the modified social score (Drews-Botsch et al, 2011).

Examination of participants: They underwent thorough physical examination, complete blood count, serum creatinine, electrolytes. Two stool samples were collected from each participant/two consecutive days, and examined within two hours. Stool samples were subjected to exanination in Department of Parasitology, Faculty of Medicine, Fayoum University.

Bacteriological examination of stool samples: Leukocyte counts of stool specimens were determined microscopically. The stool samples were inoculated on to blood agar, MacConkey agar, Mueller Hinton agar, Thiosulfate-citrate-bile salts-sucrose (TCBS) agar \& Salmonella-Shigella agar to exclude microbiological pathogens responsible for GIT clinical manifestations (Leelayoova et al, 2002). Clostridium difficile toxin A was investigated in these stool specimens with $C$. difficile toxin A test (Oxoid Ltd, UK).

Parasitological examination of stool samples: Macroscopic examination for consistency, presence of blood, mucus, or adult helminth parasites was done. For helminthic eggs and after formalin ethyl acetate sedimentation, wet smears with saline and Lugol's iodine were performed. Trichrome staining for detection of protozoal cysts, modified Ziehl-Neelsen (ZN) staining to detect enteric coccidian (Cheesbrough, 2004). For each staining method three slides were prepared from each sample.

RID $^{\circledR}$ QUICK Cryptosporidium/ Giardia/ Entamoeba Combi rapid assay (R-Biopharm, Da-rmstadt, Germany): Test was applied to all samples, according to the manufacturer's instructions. This rapid diagnostic test (RDT) is a single-step, lateral-flow, immune-chromatographic assay (ICA) that allowed the detection of specific antigens of the three protozoan parasites in a single test format. The reagents were brought to room temperature. For each fresh stool sample, 
$1 \mathrm{ml}$ of the extraction buffer was mixed with $50 \mathrm{mg}$ solid stool or $100 \mu \mathrm{l}$ of liquid stool in a test tube. Mixture was homogenized and allowed to settle for $3 \mathrm{~min}$. About $500 \mu \mathrm{l}$ of the clear supernatant was transferred into another clean tube to immerse test strip. The results were recorded after another $10 \mathrm{~min}$. Absence of control band (crimson red) indicated the invalidity of the test. Interpretation of the test for the three parasites depended on specific color band differentiation. Cryptosporidium positive gave blue color, G. intestinalis (red) and E. histolytica/dispar (green). Very faint reactions were considered negative due to difficulty to obtain another sample for confirmation.

Stool culture for Blastocystis spp.: About $50 \mathrm{mg}$ of each fecal specimen was inoculated into $5 \mathrm{ml}$ of Jones' medium $(0.01 \%$ yeast extract in buffer saline), supplemented with $20 \%$ horse serum in screw cap tubes (Jones, 1946). Tubes were incubated at $37^{\circ} \mathrm{C}$ for $48 \mathrm{~h}$ and a drop of cultured solution was examined by a light microscope at 10x \& 40x. Culture was considered negative when failed to detect Blastocystis spp. after 72h.

Stool culture for D. fragilis: Stool samples were cultured using a biphasic xenic culture system using a Loeffler's slope medium (Barratt et al, 2010), consisted of an inspissated horse serum slope with glucose (2.5 $\mathrm{g} / \mathrm{L})$, and nutrient broth No.2 $(6.25 \mathrm{~g} / \mathrm{L})$ in distilled water. About $2 \mathrm{mg}$ of rice starch was placed into the bottom of each slope. Slopes were overlaid with $5 \mathrm{ml}$ of PBS.

Statistical analysis: Package for Social Sciences for Windows, version 16 (SPSS Inc, Chicago, IL, USA) was used. Demographic and socioeconomic characteristics were treated as categorical variables and presented as frequencies and percentages. Pearson's Chi Square test and a forward stepwise logistic regression analysis were performed to identify significant predictors of infection. $P$ value $\leq 0.05$ was considered significant.

\section{Results}

Demographic data: A total of 190 subjects included in the study. The demographic and disease onset characters of the examined subjects were shown (Tab. 1). The age of subjects ranged from 18-54 years old the average was $37.3 \pm 10.1$. IBS group was significantly associated with female sex and residence in urban communities $(\mathrm{p}<0.05)$. All participants had a safe piped water supply. Most of them $(93.4 \%)$ had safe waste drainage. Participants $(24.7 \%)$ reported dealing with either pet or farm animals, and (84) $44.2 \%$ had education below secondary level.

There was neither significant differences among them as regard age, water supply, waste drainage, dealing with animals, level of education, SES, nor between disease onset and history of consumption of raw vegetables/fast or possibly contaminated food from markets or food handlers.

Table 1: Demographic and onset associated characters in different groups

\begin{tabular}{|c|c|c|c|c|}
\hline \multicolumn{2}{|l|}{ Characters } & $\begin{array}{l}\text { IBS (90) } \\
\text { No. }(\%) \\
\end{array}$ & $\begin{array}{l}\text { Normal (100) } \\
\text { No. }(\%)\end{array}$ & $P$ value \\
\hline \multirow{3}{*}{\multicolumn{2}{|c|}{$\begin{array}{c}\text { Age: }<35 \text { years } \\
\quad \geq 35 \text { years } \\
\text { mean } \pm \text { SD }\end{array}$}} & $43(47.8)$ & $46(46.0)$ & \\
\hline & & $47(52.2)$ & $54(54.0)$ & 0.806 \\
\hline & & $36.7 \pm 10.1$ & $37.5 \pm 10.4$ & \\
\hline \multicolumn{2}{|l|}{ Gender: Male/Female } & $25 / 65$ & $57 / 43$ & $<0.001 *$ \\
\hline \multicolumn{2}{|l|}{ Residence: Rural/Urban } & $30 / 60$ & $54 / 46$ & $0.015^{*}$ \\
\hline \multicolumn{2}{|l|}{ Safe water supply } & $90(100)$ & $100(100)$ & \\
\hline \multicolumn{2}{|l|}{ Safe waste drainage } & $84(93.3)$ & $94(94.0)$ & 0.85 \\
\hline \multicolumn{2}{|l|}{ Dealing with animals } & $25(27.7)$ & $22(22.0)$ & 0.357 \\
\hline \multirow[t]{2}{*}{ Level of education } & $<$ Secondary & $40(44.4)$ & $44(44.0)$ & \multirow{2}{*}{0.95} \\
\hline & $\geq$ Secondary & $50(55.6)$ & $56(56.0)$ & \\
\hline \multirow[t]{3}{*}{ SES } & Low & $43(47.8)$ & $44(44.0)$ & \multirow[t]{3}{*}{0.56} \\
\hline & Moderate & $36(40.0)$ & $47(47.0)$ & \\
\hline & High & $11(12.2)$ & $9(9.0)$ & \\
\hline Consumption of raw food & No & $30(33.3)$ & $49(50.0)$ & 0.06 \\
\hline Or contaminated food & Not sure & $60(66.7)$ & $51(51.0)$ & \\
\hline
\end{tabular}


Clinical pictures: The most prominent abdominal symptoms reported by IBS cases were abdominal pain either colicky or vague abdominal pain $52(57.8 \%)$, abdominal distention and bloating $31(34.4 \%)$, sensation of incomplete evacuation of stool $26(28.9 \%)$, nausea or vomiting 12(13.3), unexplained weight loss within last 4 months 6(6.7\%). IBS group was classified according to the common bowel habits using Rome III criteria into diarrhea dominant (IBS-D), constipation dominant (IBS-C), and alternative bowel pattern (IBS-A). Frequency distributions were $32(35.6 \%), 18(20 \%) \& 40(44.4 \%)$, respectively. According to bowel habits all control group had regular, normal habits.

Examination of stools (Figs. 1 \& 2): No blood, mucous, helminthic eggs, worms or parts of them were detected. Cysts of Entamoeba coli (E. coli). E. complex, G. intestinalis, oocysts of Cryptosporidium spp. were found in both groups without any significant difference $(P \geq 0.05)$. ICA increased detection rate of E. complex, G. intestinalis, Cryptosporidium spp. than direct parasitolo-gical methods and the estimated sensitivity rates (SN) in comparison with trichrome stain were $100 \%$ for the three parasites. The estimated specificity rates (SP) were $95.5 \%$ for E. complex, $95.0 \%$ for G. intestinalis \&
98.2\% for Cryptosporidium spp. (Tab. 2). Blastocystis spp. and D. fragilis were hardly detected by wet mount (5 and 0 cases) and increased by trichrome stain (28 and 11 cases), respectively. The detection rate increased by using culture reaching up to $43 / 190$ (22.6\%), 29/190 (15.3\%), respectively, to be the most detectable parasites in examined samples. The SN \& SP of trichrome stain in comparison with the standard culture techniques were estimated for Blastocystis sp. and $D$. fragilis. The $\mathrm{SN}$ rates were $65 \%$ and $37.9 \%$ and SP rates were $100 \%$ for the two parasites respectively (Tab. 2). Both parasites were significantly detected in IBS group $(34.4 \%, 22.2 \%)$, than control group $(12.0 \%, 9.0 \%)(P<0.001 \& 0.02)$, respectively. The commonly encountered parasites were Blastocystis, D. fragilis \& Cryptosporidium spp. 43, $29 \& 22$ cases, respectively.

The parasites detected rate in IBS-subgroups was presented (Fig. 3): Cryptosporidium, G. intestinalis and E. histolytical dispar were significantly higher in cases with IBS-D as compared to other subgroups. Blastocystis spp. was equally detected in both IBS-D \& IBS-A but wasn't detected in IBS-C. Entamoeba coli cysts was significantly higher in IBS-C cases as compared to other IBS subgroups.

Table 2: Sensetivity and specificity of diagnostic techniques

\begin{tabular}{|l|c|c|c|c|}
\hline \multicolumn{1}{|c|}{ Parasite (total positive cases detected) } & \multicolumn{2}{|c|}{ No. of positive cases detected by each method (n) } & Sensetivity $\%$ & Specificity \% \\
\hline G. ${\text { intestinalis }(18)^{\mathrm{a}}}^{\mathrm{a}}$ & Microscopy (9) & ICA (18) & 100 & 95 \\
\hline E. complex $(18)^{\mathrm{a}}$ & Microscopy (10) & ICA (18) & 100 & 95.5 \\
\hline Cryptosporidium spp. $(22)^{\mathrm{a}}$ & ZN stain (19) & ICA (22) & 100 & 98.2 \\
\hline Blastocystis spp. $(43)^{\mathrm{b}}$ & Microscopy (28) & Culture (43) & 65 & 100 \\
\hline D. fragilis $(29)^{\mathrm{b}}$ & Microscopy (11) & Culture (29) & 37.9 & 100 \\
\hline
\end{tabular}

${ }^{\text {a }}$ Sensitivity \& specificity of ICA measured to microscopy standard technique (ST) for detection of G. intestinalis, E. complex, and Cryptosporidium spp. ' ${ }^{\mathrm{b}}$ Sensitivity \& specificity of microscopy measured to culture ST for detection of Blastocystis spp.and D. fragilis

Relation of demographic characters and prevalent parasitic infections:The study tried to find any association between demographic charcaters of cases and the prevalence of the three common parasites. There was no statistical association between age, sex, or the lower education with the three prevalent protozoa (Tab. 3). The three parasites were associated with the residence in rural communities, lower SES, unsafe waste drainage, and was significantly detected in cases with a history of possible consumption of contaminated food, or dealing with animals $(P<0.001)$. 
Table 3: Association between three prevalent protozoal infections and the demographic characters of cases

\begin{tabular}{|c|c|c|c|c|c|c|c|}
\hline \multirow[t]{2}{*}{ Factors } & \multirow{2}{*}{$\begin{array}{l}\text { Total cases } \\
(190)\end{array}$} & \multicolumn{2}{|c|}{ Blastocystis spp. (43) } & \multicolumn{2}{|c|}{ D. fragilis (29) } & \multicolumn{2}{|c|}{ Cryptosporidium (22) } \\
\hline & & No. $(\%)$ & $P$ value & No. $(\%)$ & $P$ value & No. $(\%)$ & $P$ value \\
\hline \multirow[t]{2}{*}{ Age } & $\leq 35$ years $(89)$ & $18(20.2)$ & \multirow[t]{2}{*}{0.46} & $15(16.9)$ & \multirow[t]{2}{*}{0.57} & $8(9.0)$ & \multirow[t]{2}{*}{0.3} \\
\hline & $>35$ years $(101)$ & $25(24.8)$ & & $14(13.9)$ & & $14(13.9)$ & \\
\hline \multirow[t]{2}{*}{ Gender } & Female (108) & $23(21.3)$ & \multirow[t]{2}{*}{0.61} & $19(17.6)$ & \multirow[t]{2}{*}{0.31} & $15(13.9)$ & \multirow[t]{2}{*}{0.25} \\
\hline & Male (82) & $20(24.4)$ & & $10(12.2)$ & & $7(8.5)$ & \\
\hline \multirow[t]{2}{*}{ Residence } & Rural (84) & $34(40.5)$ & \multirow[t]{2}{*}{$<0.001 *$} & $20(23.8)$ & \multirow[t]{2}{*}{$0.004 *$} & $20(23.8)$ & \multirow[t]{2}{*}{$<0.001 *$} \\
\hline & Urban (106) & $9(20.9)$ & & $9(8.5)$ & & $2(1.9)$ & \\
\hline \multirow[t]{3}{*}{ SES } & Low (87) & $36(41.4)$ & \multirow[t]{3}{*}{$<0.001^{*}$} & $23(26.4)$ & \multirow{3}{*}{$\begin{array}{l}<0.001 \\
*\end{array}$} & $21(24.1)$ & \multirow[t]{3}{*}{$<0.001 *$} \\
\hline & Moderate (83) & $6(7.2)$ & & $5(6.0)$ & & $1(1.2)$ & \\
\hline & High (20) & $1(5.0)$ & & $1(5.0)$ & & $0(0.0)$ & \\
\hline \multirow[t]{2}{*}{ Education level } & $<$ Secondary (84) & $23(27.4)$ & \multirow[t]{2}{*}{0.164} & $11(13.1)$ & \multirow[t]{2}{*}{0.46} & $7(8.3)$ & \multirow[t]{2}{*}{0.21} \\
\hline & $\geq$ Secondary (106) & $20(18.9)$ & & $18(17.0)$ & & $15(14.2)$ & \\
\hline \multirow{2}{*}{$\begin{array}{ll}\begin{array}{l}\text { Safe } \\
\text { drainage }\end{array} & \text { waste } \\
\end{array}$} & No (12) & $7(58.3)$ & \multirow[t]{2}{*}{$0.002 *$} & $6(50.0)$ & \multirow[t]{2}{*}{$0.001 *$} & $6(50.0)$ & \multirow[t]{2}{*}{$<0.001 *$} \\
\hline & Yes (178) & $36(20.2)$ & & $23(12.9)$ & & $16(9.0)$ & \\
\hline \multirow{2}{*}{$\begin{array}{l}\text { Raw or conta- } \\
\text { minated food }\end{array}$} & No (79) & $4(5.1)$ & \multirow{2}{*}{$<0.001 *$} & $4(5.1)$ & \multirow{2}{*}{$\begin{array}{l}<0.001 \\
*\end{array}$} & $0(0.0)$ & \multirow[t]{2}{*}{$<0.001 *$} \\
\hline & Yes \& may be (111) & $39(35.1)$ & & $25(22.5)$ & & $22(19.8)$ & \\
\hline \multirow{2}{*}{$\begin{array}{l}\text { Dealing with } \\
\text { animals }\end{array}$} & No (143) & $10(7.3)$ & \multirow[t]{2}{*}{$<0.001 *$} & $7(4.9)$ & \multirow{2}{*}{$\begin{array}{l}<0.001 \\
*\end{array}$} & $3(2.1)$ & $<0.001$ \\
\hline & Yes (47) & $33(70.2)$ & & $22(46.8)$ & & $19(40.4)$ & \\
\hline
\end{tabular}

*significant difference

Forward regression analysis was used to detect the significant risk factors for the three common protozoal parasites (Tab. 4). IBS was at risk of Blastocystis infection in comparison to control with an odds ratio $(95 \% \mathrm{CI})$ of 11.61 (3.1-34.68). Dealing with animals was reported as a common risk factor for the three parasitic infections. The OR was 25.37 for Blastocystis infection, 24.13 for D. fragilis infection and 6.6 for Cryptosporidium infection. The low SES was reported as risk for Blastocystis and Cryptosporidium with OR 3.08 (1.05-9.01) and 11.9 (1.5-98.7), respectively. Consumption of possibly contaminated food and/or drink was associated with Blastocystis infection with OR 3.74 (1.04-13.47).

Table 4: Forward regression analysis for detection of risk factors for three common protozoal parasites

\begin{tabular}{|l|l|c|c|c|c|c|c|}
\hline \multirow{2}{*}{ Predictors } & \multicolumn{2}{|c|}{ Blastocystis spp. infection } & \multicolumn{3}{|c|}{ D. fragilis infection } & \multicolumn{2}{c|}{ Cryptosporidium infection } \\
\cline { 3 - 8 } & $P$ value & OR $(95 \%$ CI $)$ & $P$ value & OR $(95 \%$ CI $)$ & $P$ value & OR (95\%CI) \\
\hline Group & IBS / control & $<0.001^{*}$ & $11.61(3.1-34.68)$ & 0.070 & $2.6(0.925-7.335)$ & 0.206 & $2.9(0.15-1.51)$ \\
\hline SES & Low vs. high \& middle & $0.040^{*}$ & $3.08(1.05-9.01)$ & 0.224 & $2.3(0.6-8.86)$ & 0.021 & $11.9(1.5-98.7)$ \\
\hline Residence & Rural vs. urban & 0.070 & $0.28(0.07-1.1)$ & 0.179 & $3.49(0.56-21.7)$ & 0.504 & $0.51(0.07-2.65)$ \\
\hline Safe waste disposal & Yes vs. no & .0 .423 & $1.927(0.39-9.58)$ & 0.399 & $0.54(0.128-2.26)$ & 0.363 & $0.51(0.12-2.19)$ \\
\hline Contaminated food & Yes vs. no & 0.043 & $3.74(1.04-13.47)$ & 0.575 & $1.53(0.35-6.75)$ & 0.996 & $1.6(0.8-3.9)$ \\
\hline Animal dealing & Yes vs. no & $0.001^{*}$ & $25.37(6.73-95.59)$ & $0.001^{*}$ & $24.13(4.48-129.9)$ & $0.028^{*}$ & $6.6(1.2-35.62)$ \\
\hline
\end{tabular}

\section{Discussion}

IBS is a multi-factorial disorder with lack of knowledge regarding its underlying mechanism. Intestinal parasitic infections have been proposed as possible inducing agents (Vasquez-Rios et al, 2016).

In this study, Blastocystis spp. was detected in $12.0 \%$ of healthy samples and in $34.4 \%$ of IBS samples, while El-Badry et al. (2018) positively grown Blastocystis spp. from the stool of IBS cases at a rate of $19.1 \%$ using the same culture technique. In this study, Blastocystis spp. was the most detectable parasite in the total examined samples 43/190(22.6\%). This parasite was previously reported as the most widely dis- tributed, with prevalence rates ranged from $1.5 \%$ \& $10 \%$ in developed countries to $30 \%$ and $50 \%$ in developing countries, respectively (Vasquez-Rios et al, 2016). Its prevalence may vary within the same country.

The regression analysis showed that IBS cases were 11.61 times at risk to acquire this infection more than control group in accordance with Yakoob et al. (2010 a\&b) and Jimenez-Gonzalez et al. (2012). The results disagreed with other studies that revealed non-significant difference between the two groups as regard this parasite (Tungtrongchitr et al, 2004; Ramirez-Miranda et al, 2010; Surangsrirat et al, 2010; Cekin et al, 2012; Morgan, et al, 2012). In two studies a 
higher Blastocystis infection rate was found in control $(71 \%, 22.1 \%)$ than IBS $(49 \%$ \& $14.5 \%$ ) by Vasquez-Rios et al. (2015) and Krogsgaard et al. (2015), respectively.

In experimental animals it was proved that Blastocystis ST4 by contact with epithelial cells induce their apoptosis, thus causing an increase in the cell permeability (Lepczynska et al, 2016). Another study proved that the parasite degrade mucine glycoproteins through its cysteine and serine proteases enzymes to obtain its needs of carbohydrates and proteins (Poirier et al, 2012). Additionally, continuous exposure to parasite antigens are accused for paracellular permeability changes, inflammation and hypersensitivity in the host intestinal mucosa (Stark, 2007; Lepczyńska et al, 2016).

This study hypothesized that the D. fragilis should be higher in IBS cases. However, regression analysis revealed no association of this parasite with the IBS group in agreement with (Jimenez-Gonzalez et al., 2012: Krogsgaard et al, 2015), while disagreeing with Yakoob et al. (2010b). The present results revealed the nearly equal distribution of $D$. fragilis in cases of IBS-D \& IBS-C. However, D. fragilis was significantly higher in cases with IBS-D cases (Yakoob et al, 2010b) and more prevalent association with IBS-C (Krogsgaard et al, 2015). Thus, D. fragilis might be a prevalent parasitological infection, detected in both the IBS and healthy controls.

In the present study, Cryptosporidium infection wasn't a significant risk factor. No clear reports, in humans, linked this parasite with IBS, since, cryptosporidiosis is usually a cause of self-limiting diarrhea in immunocompetent individuals, but severe diarrhea and dissemination to extra-intestinal sites can occur in high-risk individuals. However, the obtained results proved that Cryptosporidium was one of the most prevalent parasites. The total detection rate was higher than (Banisch et al, 2015). This may be explained by being associated with large waterborne outbreaks and contamination of foods like vegetables, through poultry feces used as sources of manure (Banisch et al, 2015).

The present results, revealed that Giardia detection rate using ICA reached up to $11.1 \%$ in the IBS group higher than control group $8 \%(P=0.47)$. These results agreed with Hanevik et al. (2009), who found that $11-14 \%$ of IBS cases had Giardia infection but, without proving association with IBS in agreement with (Morgan et al, 2012; Krogsgaard et al, 2015; Vasquez-Rios et al, 2015). But, abdominal symptoms might closely simulate IBS symptoms, after this infection (Hanevik et al, 2009).

Thus, Giardia should be ruled out as a possible cause in patients with IBS-like symptoms, and cases should be followed to avoid the future risk of developing IBS (VasquezRios et al, 2015).

The present showed no association between IBS \& E. histolytica the only pathogenic form that agreed with many authors (Ramirez-Miranda et al, 2010; Morgan, et al, 2012; Krogsgaard et al, 2015; VasquezRios et al, 2016). However, the number of E. histolytica/ dispar parasites in study samples was 9.5\% using ICA, in range with (Banisch et al, 2015).

No helminthic infections were diagnosed using direct parasitological techniques as diagnosis depends on the expertise of technicians. This opinion was supported by the increased rate of protozoa detection by culture (Elghareeb et al, 2015; Barratt et al, 2010), or ICA for diagnosis in comparison with the low detection rate of $E$. coli depending on microscopy. The estimated SN and SP rates of ICA in comparison to standard microscopy were in range with previous studies (Abdel Hameed et al, 2008; Goñi et al, 2011; Banisch et al, 2015). In addition to ease of application without the need of skilled technicians. In this study, the culture was used as Blastocystis spp. standard diagnostic technique (Dogruman-Al et al, 2010; Elghareeb et al, 2015). The estimated SN and SP of trichrome stain compared to cul- 
ture were in range given by Elghareeb et al. (2015) and Dogruman-Al et al. (2010) who found SN rate of $50 \%$ and SP rate of $100 \%$.

According to the regression analysis, the common serious risk factor associated with Blastocystis, D. fragilis and Cryptosporidium infections was the animals contact (Wawrzyniak et al. (2013). Other factors were low SES, and rural residence, consumption of possibly contaminated food and drink in agreement with (Souppart et al., 2010). El-Badry et al. (2018) reported that IBS cases from rural areas were at risk of acquiring Blastocystis infection ten times more than those in urban areas. Since fecooral route is considered the main mode of transmission of these parasites, with the chance for zoonotic transmission of infection (Wawrzyniak et al, 2013). This was based on a higher prevalence in developing countries compared with developed countries. but, another study revealed that having a high income, no pet animals, and daily intake of bottled water were associated with Blastocystis (Krogsgaa-rd et al, 2015).

This study tried as possible to avoid the common limitations of previous studies by choosing asymptomatic normal controls, and excluding those with a previous history of exposure to antibiotics to avoid dysbiosis affecting especially Blastocystis and D. fragilis prevalence rates.

\section{Conclusion}

No doubt, the use of RIDA ${ }^{\circledR}$ QUICK ICA and cultures for accurate detection of parasitic protozoa avoided missing cases due to low sensitive microscopy.

The IBS cases are at risk of Blastocystis infection. Further studies are needed to assess the role and the epidemiological association between intestinal parasites and IBS using PCR for diagnosis and subtype analysis of parasitic infections.

\section{References}

Abdel Hameed, DM, Elwakil, HS, Ahmed, MA, 2008: A single-step immunochromatographiclateral-flow assay for detection of $\mathrm{Gi}^{-}$ ardia lamb-lia and Cryptosporidium parvum antigens in human fecal samples. J. Egypt Soc. Parasitol. 38, 3:797-804.

Banisch, DM, El-Badry, A, Klinnert, JV, Ignatius, R, El-Dib, N, 2015: Simultaneous detection of Entamoeba histolytica/dispar, Giardia duodenalis and Cryptosporidia by immunochromatographic assay in stool samples from patients living in the Greater Cairo Region, Egypt. World J. Microbiol. Biotechnol. 31, 8: 1251-8.

Barratt, JL, Banik, GR, Harkness, J, Marriott, D, Ellis, JT, et al, 2010: Newly defined conditions for the in vitro cultivation and cryopreservation of Dientamoeba fragilis: new techniques set to fast track molecular studies on this organism. Parasitology 137, 13:1867-78.

Cekin, AH, Cekin, Y, Adakan, Y,Tasdemir, E, Koclar, FG, et al, 2012: Blastocystosis in patients with gastrointestinal symptoms: a casecontrol study. BMC Gastroenterol. 12:122-8.

Cheesbrough, M, 2004: District Laboratory Practice in Tropical Countries. $2^{\text {nd }}$ edition. Cambridge: Cambridge University Press.

Dogruman-Al, F, Simsek, Z, Boorom, K, Ekici, E, Sahin, M, 2010: Comparison of methods for detection of Blastocystis infection in routinely submitted stool samples, and also in IBS/IBD patients in Ankara, Turkey. PLoS One. 5: e15484.

El-Badry, AA, Abd El Wahab,WM, Hamdy, DA, Aboud, A, 2018: Blastocystis subtypes isolated from irritable bowel syndrome patients and co-infection with Helicobacter pylori. Parasitol. Res. 117:127-37.

Elghareeb, AS, Younis, MS, El Fakahany, A F, Nagaty, IM, Nagib, MM, 2015: Laboratory diagnosis of Blastocystis spp. in diarrheic patients. Trop. Parasitol. 5, 1:36-41.

Drews-Botsch, C, Schieve, LA, Kable, J, Coles, C, 2011: Socioeconomic differences and the impact of being small for gestational age on neurodevelopment among preschool-aged children. Rev. Environ. Hlth. 26, 3:221-9..

Goñi, P, Martín, B, Villacampa, M, García, A, Seral, C, et al, 2012: Evaluation of an immunochromatographic dip strip test for simultaneous detection of Cryptosporidium spp, Giardia duodenalis, and Entamoeba histolytica antigens in human faecal samples. Eur. J. Clin. Microbiol. Infect. Dis. 31:2077-82.

Hanevik, K, Dizdar, V, Langeland, N, Hausken, T, 2009: Development of functional gastrointestinal disorders after Giardia lamblia infection. BMC Gastroenterol. 9:27-31. 
Jimenez-Gonzalez, DE, Martinez-Flores, WA, Reyes-Gordillo, J, Ramirez-Miranda, ME, Arroyo-Escalante, S, et al, 2012: Blastocystis infection is associated with irritable bowel syndrome in a Mexican Patient Population. Parasitol. Res. 110, 3:1269-75.

Jones, WR, 1946: The experimental infection of rats with Entamoeba histolytica; with a method for evaluating the anti-amoebic properties of new compounds. Ann. Trop. Med. Parasitol. 40: 130-40.

Klem, F, Wadhwa, A, Prokop, LJ, Sundt, W J, Farrugia, G, et al, 2017: Prevalence, risk factors, and outcomes of irritable bowel syndrome after infectious enteritis: A systematic review and meta-analysis. Gastroenterol. 152, 5: 1042-54.

Krogsgaard, LR, Engsbro, AL, Stensvold, C R, Nielsen, HV, Bytzer, P, 2015: The prevalence of intestinal parasites is not greater among individuals with irritable bowel syndrome: A population-based case-control study. Clin. Gastroenterol. Hepatol. 13, 3:507-13.

Leelayoova, S, Taamasri, P, Rangsin, R, Naaglor, T, Thathaisong, U, et al, 2002: In-vitro cultivation: A sensitive method for detecting Blastocystis hominis. Ann. Trop. Med. Parasitol. 96, 8:803-7.

Lepczyńska, M, Dzika, E, Kubiak, K, Korycińska, J, 2016: The role of Blastocystis sp. as an etiology of irritable bowel syndrome. Polish Ann. Med. 23, 1:57-60.

Longstreth, GF, Thompson, WG, Chey, WD, Houghton, LA, Mearin, F, et al, 2006: Functional bowel disorders. Gastroenterol. 130:148091

Morgan, DR, Benshoff, M, Cáceres, M, Becker-Dreps, S, Cortes, L, et al, 2012: Irritable bowel syndrome and gastrointestinal parasite infection in a developing nation environment. Gastroenterol. Res. Pract.343812. doi:10.1155/2012/ Poirier, P, Wawrzyniak, I, Vivarès, CP, Delbac, F, El Alaoui, H, 2012: New insights into Blastocystis spp.: a potential link with irritable bowel syndrome. PLoS Pathog. 8, 3: e1002545.

Ramirez-Miranda, ME, Hernandez-Castellanos, R, Lopez-Escamilla, E, Moncada, D, Rodrigu-ez-Magallan, A, et al, 2010: Parasites in Mexican patients with irritable bowel syndrome:
A case-control study. Parasit. Vectors 3:96-9.

Souppart, L, Moussa, H, Cian, A, Sanciu, G, Poirier, P, El, et al, 2010: Subtype analysis of Blastocystis isolates from symptomatic patients in Egypt. Parasitol. Res. 106:505-11.

Stark, D, van Hal, S, Marriott, D, Ellis, J, Harkness, J, 2007: Irritable bowel syndrome: a review on the role of intestinal protozoa and the importance of their detection and diagnosis. Int. J. Parasitol. 37, 1:11-20.

Surangsrirat, S, Thamrongwittawatpong, L, Piyaniran, W, Naaglor, T, Khoprasert, C, et al, 2010: Assessment of the association between Blastocystis infection and irritable bowel syndrome. J. Med. Assoc. Thai. 93:119-24.

Thabane, M, Kottachchi, DT, Marshall, JK, 2007: Systematic review and meta-analysis: The incidence and prognosis of post-infectious irritable bowel syndrome. Aliment. Pharmacol. Ther. 26:535-44.

Tungtrongchitr, A, Manatsathit, S, Kositchaiwat, C, Ongrotchanakun, J, Munkong, $\mathrm{N}$, et al, 2004: Blastocystis hominis infection in irritable bowel syndrome patients. Southeast Asian J. Trop. Med. Pub. Hlth. 35, 3:705-10.

Vasquez-Rios, G, Machicado, JD, Terashima, A, Marcos, LA, 2016: Irritable bowel syndrome and intestinal parasites: A view from South America. Rev. Gastroenterol. Peru 36, 2:153-8.

Vasquez-Rios, G, Machicado, JD, Gamero, M T, Pezua, A, Betancourt, AB, et al, 2015: Evaluating the role of intestinal parasites in the high rates of irritable bowel syndrome in South America: A pilot study. Folia Parasitol. (Praha) 11, 62. pii:2015.065.

Wawrzyniak, I, Poirier, P, Viscogliosi, E, Dionigia, M, Texier, C, et al, 2013: Blastocys-tis, an unrecognized parasite: an overview of pathogenesis and diagnosis. Ther. Adv. Infect. Dis. 1, 5:167-78.

Yakoob, J, Jafri, W, Beg, MA, Abbas, Z, Naz, S, et al, 2010a: Irritable bowel syndrome: Is it associated with genotypes of Blastocystis hominis. Parasitol. Res. 106, 5:1033-8.

Yakoob, J, Jafri, W, Beg, MA, Abbas, Z, Naz, S, et al, 2010b: Blastocystis hominis and Dientamoeba fragilis in patients fulfilling irritable bowel syndrome criteria. Parasitol. Res. 107, 3: 679-84

\section{Explanation of figures}

Fig. 1: To left protozoa detected by stool examination X100; $(1,2)$ Blastocystis spp. iodine and trichrome stains $(3)$ D. fragilis trichrome stain, (4) E. coli cyst iodine stain, (5) E. histolytica cyst trichrome stain $(6,7) G$. intestinalis cysts iodine, trichrome stains (8) Cryptosporidium spp. modified ZN stain. To right ICA strip showing positive and negative results. 
Fig. 2: Protozoa detected in groups, *significant difference between IBS and controls. Fig. 3: Various parasites in IBS-subgroups, ${ }^{*}$ significant difference between groups

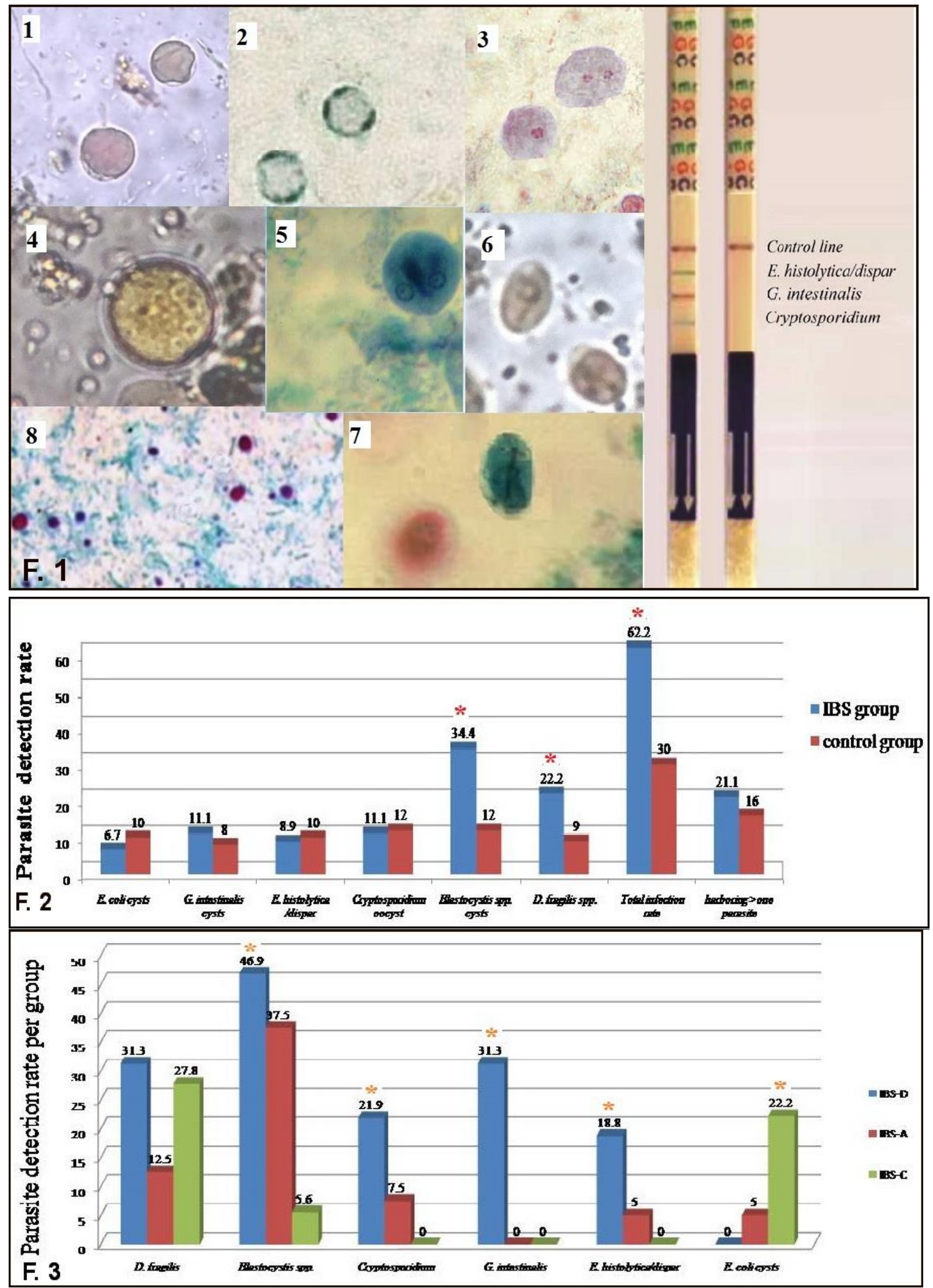

